\title{
Management of environmental and economic risks of mining enterprises
}

\author{
Aleksey Khoreshok*, Natalya Kudrevatyh, Tatiana Koroleva, and Dmitriy Islamov \\ T. F. Gorbachev Kuzbass State Technical University, 650000 Kemerovo, 28 Vesennyaya st., Russian \\ Federation
}

\begin{abstract}
A methodology for assessing the environmental and economic risks of mining enterprises is proposed. The risk characteristics are determined. Proactive measures are proposed in accordance with the development strategy of Kuzbass.
\end{abstract}

\section{Introduction}

One of the most important factors hindering the balanced and stable development of mining regions is environmental and economic risk, the analysis and assessment of which must be considered as integral parts of the rational nature management mechanism. At the same time, the essential characteristics of environmental and economic risks do not allow limiting their management only by the level of an economic entity. In this regard, the problem of developing and implementing an effective regional mechanism for managing the environmental and economic risks of mining enterprises is relevant.

\section{Characteristic of the work}

The mining industry in the Russian Federation is the backbone of the country's economy. In the structure of the gross domestic product, it occupies $10 \%$. At the same time, largescale structural changes in the external environment reduce the likelihood of successful development of the industry in the future. The key negative factor is global climate solutions, as the mining industry is closely related to $\mathrm{CO} 2$ emissions, namely the exploration, production and sale of carbonaceous raw materials, as well as ore processing and metalworking [1].

As a result, the world's largest mining companies are under public scrutiny and must respond faster than others to changing conditions. Despite the fact that in the annual reports of mining companies almost everyone notes the environmental effect from the implementation of measures to reduce the environmental impact, it is not enough to maintain a positive image. In addition, mining companies should take into account that public opinion is formed not so much from the standpoint of the environmental hazard of their type of activi-

* Corresponding author: haa.omit@kuzstu.ru 
ty, as from the consequences of using their products throughout the production chain. This means that the industry can only increase trust and demand for its products by uniting with coal consumers and implementing joint environmental solutions.

Despite the fact that coal accounts for more than $30 \%$ of the world's energy balance, innovative technologies that reduce coal consumption reduce investment interest in this industry. Based on the results of the analysis of the activities of the largest mining companies in the world, the key areas of their long-term strategy are: ensuring production safety, social support for employees and reducing the harmful impact on the environment. At the same time, environmental threats are associated with the specifics of companies' activities and the regulatory environment. Implementation of programs to improve the environmental efficiency of production, the introduction of innovative technologies, and compliance with legal and corporate standards are proposed as management mechanisms. According to the public annual reports of the largest mining companies in the Russian Federation, the environmental risk is assessed as high, and the probability of this risk exceeds $70 \%$. All companies point to global climate solutions as the key drivers of this risk.

Kuzbass is a developed industrial region, in which more than 45 thousand enterprises operate, fifty of which are the flagships of the coal, metallurgical and chemical industries. Extraction of minerals accounts for $36 \%$ of the gross regional product. Such concentration of industrial production inevitably entails a great burden on the environment. [2,3]. At present, Kuzbass ranks second in the Siberian Federal District after the Krasnoyarsk Territory in terms of environmental pollution. The analysis of the level of sustainable development of the region by groups of indicators over the past 10 years indicates significant environmental problems. If social and economic indicators improve, then among environmental indicators, 5 out of 6 deteriorate significantly. The mortality rate in the region is increasing, with almost half of deaths due to causes directly related to the unfavorable environmental situation in the region: blood diseases and neoplasms. Among social indicators, the negative trend is driven by those that are directly or indirectly related to the state of the environment, for example, an increase in morbidity. Thus, the unfavorable environmental situation hinders sustainable development [4].

Analysis of the industrial potential of the Kemerovo region and forecasts of the development of world energy markets made it possible to identify two possible development scenarios:

1.Extensive growth (inertial development). Growth due to the strengthening of the region's raw materials specialization (increasing production and primary processing) while maintaining the basic sector of the economy. Maintaining the role of coal in the energy balance, maintaining the level of exports, paying attention to the quality of finished products and reducing transport costs. Result: stagnation and long-term decline in indicators of sustainable development of the region.

2. Intensive growth (innovative development). Achieving competitiveness based on the growth of technologies and human capital (production supported by an increase in processing depth and new types of production), diversification of the economy. Expanding sources of growth through renewable resources: knowledge economy, technology, deep processing of coal. Result: improvement of indicators of sustainable development of the region.

The probability of the first, inertial scenario is higher, especially in connection with the recent changes in the geopolitical system and in the world commodity markets. The implementation of this scenario will mean an increase in the likelihood of the onset of the consequences of environmental and economic risks [5].

Analysis of the existing methods for assessing environmental risks revealed a number of shortcomings: 
1. Equating the assessment of environmental and economic risks with the assessment of economic damage from the onset of risks.

2. Equating the assessment of environmental and economic risks to the assessment of the likelihood of risks.

3. Economic assessment of damage without taking into account the duration of the negative impact and the spatial distribution of the risk impact.

4. Lack of an integrated approach to assessing environmental and economic risks [6].

For the most part, the existing methods are aimed at assessing the economic damage from the impact of risks, thereby replacing the concept of risk and the consequences of risk, or only the probability of risk occurrence is assessed. In addition, there is practically no possibility in the methods of assessing the delayed impact and the severity of consequences.

In order to develop a comprehensive assessment methodology, the definition of environmental and economic risks was clarified as the probability of a decrease in the sustainable development of a mining region under the influence of anthropogenic and technogenic loads on the territory. The characteristics are the probability of the risk occurrence, the harmfulness - that is, the losses caused by the risk, the magnitude, that is, the prevalence of the risk relative to the objects of influence, the duration, that is, the prevalence of risk in time, and the prevalence of the risk relative to the area of impact. For a quantitative assessment of the considered characteristics, estimated indicators have been developed (table 1).

Table 1. Characteristics and estimated indicators of environmental and economic risks

\begin{tabular}{|l|l|l|}
\hline \multicolumn{1}{|c|}{ Characteristic } & \multicolumn{1}{|c|}{ Indicators } & \multicolumn{1}{c|}{ Calculation method } \\
\hline $\begin{array}{l}\text { Probability of risk } \\
\text { occurrence }\end{array}$ & $\begin{array}{l}\text { The coefficient of prob- } \\
\text { ability of risk }\end{array}$ & $\begin{array}{l}\text { The ratio of the sum of the estimated risk } \\
\text { probability to the number of expert estimates } \\
\text { of the probability }\end{array}$ \\
\hline Harmfulness & $\begin{array}{l}\text { Risk harmfulness } \\
\text { coefficient }\end{array}$ & $\begin{array}{l}\text { The ratio of the value of economically ex- } \\
\text { pressed losses to the value of net regional } \\
\text { income }\end{array}$ \\
\hline Scale & A ratio of the scale & $\begin{array}{l}\text { The ratio of the number of unique objects that } \\
\text { are harmed to the total number of unique } \\
\text { objects (for example, population, water bod- } \\
\text { ies, fauna, etc.) }\end{array}$ \\
\hline Duration & $\begin{array}{l}\text { Exposure duration } \\
\text { factor }\end{array}$ & $\begin{array}{l}\text { The ratio of the period of the harmful impact } \\
\text { of the risk, during which the damage is re- } \\
\text { peated or increases, to the duration of the } \\
\text { forecast period }\end{array}$ \\
\hline Prevalence & $\begin{array}{l}\text { The ratio of the physical characteristics of the } \\
\text { target (area, volume, population, etc.) to the } \\
\text { analogous characteristics of the region as a } \\
\text { whole }\end{array}$ \\
\hline
\end{tabular}

These indicators are proposed to be used for a comprehensive assessment based on a matrix of risk indicators: the probability of occurrence and the significance of consequences. The estimation algorithm includes the following stages:

1.Calculation of indicators reflecting the characteristics of environmental and economic risks

2.Estimation of the coefficients of elasticity of these indicators in relation to the level of sustainable development of the region

3.Calculation of a complex indicator of the significance of environmental and economic risk by the formula (1) 


$$
Z i=\left(\sum_{J=1}^{n} X j * K j\right) / \mathrm{n}
$$

где $X j$ - value of the $j$-th indicator of the $i$-th risk; $K j$ - coefficient of elasticity of the $j$ th indicator.

4. Evaluation of the probability of the onset of environmental and economic risk by the formula (2)

$$
V i=\sum B / n
$$

where $B$ - the sum of expert estimates of the probability of risk occurrence, $\% ; n-$ the number of expert assessments.

5. Construction of a matrix of environmental and economic risks by functions of probability and significance and determination of the risk zone

As a result, for all the identified risks, we obtain a two-component indicator in the form of a matrix, which can be used as a basis for making management decisions. Depending on the combination of the values of the $Z i$ and $V i$ indicators, four risk zones are possible: insignificant, probabilistic, permissible and critical.

The proposed methodology makes it possible to assess not only the current environmental and economic risks, but can also be an assessment tool for the mechanism of their management. The mechanism for managing environmental and economic risks at the regional level includes four main blocks.

The first block includes procedures for the formation and segmentation of environmental initiatives, the creation of a complete list of initiatives, the elaboration of development scenarios and an assessment of their effectiveness in terms of reducing both the likelihood of risks and the significance of their manifestation.

The second block includes standards for interaction of the three-tier system, including ensuring organizational and economic conditions for environmental safety, creating conditions for restructuring the economy, coordinating the interests of all participants in the process to reduce environmental and economic risks.

The third block includes normative and legislative acts in relation to the developed system of environmental and economic risk management, the adoption, within the respective territory, of legislative acts, standards and rules establishing the institutional "structural" and functional "process" organization for the implementation of the strategy, including : the establishment of a territorial institutional order, the establishment of specific values of the parameters of environmental safety, the impact on business entities in the direction of reducing environmental and economic risks, improving the regional environmental and economic policy.

The fourth block includes a strategy for reducing environmental and economic risks. Strategy development begins with the development of realistic environmental and economic policy goals for the long term. Then, an assessment of the occurrence and consequences of environmental and economic risks is carried out in accordance with the assessment methodology developed above. The development of a strategy is being completed with the formation of institutions for managing environmental and economic risks, instrumental and methodological support.

The method proposed above was applied to assess the risk of increasing dust formation during the expansion of open pit mining (table 2).

Table 2. Risk assessment "Increase in dust formation during the expansion of open pit mining"

\begin{tabular}{|c|l|c|}
\hline № & \multicolumn{1}{|c|}{ Indicators } & \multicolumn{1}{c|}{ Rating } \\
\hline 1. & The coefficient of probability of risk & 0,65 \\
\hline 2. & Risk harmfulness coefficient & 0,05 \\
\hline
\end{tabular}


Table 2 continuation

\begin{tabular}{|c|l|l|}
\hline № & \multicolumn{1}{|c|}{ Indicators } & \multicolumn{1}{c|}{ Rating } \\
\hline 3. & Coefficient of elasticity $\mathrm{K}_{1}$ & 0,8 \\
\hline 4. & A ratio of the scale & 0,8 \\
\hline 5. & Coefficient of elasticity $\mathrm{K}_{2}$ & 0,12 \\
\hline 6. & Exposure duration factor & 0,95 \\
\hline 7. & Coefficient of elasticity $\mathrm{K}_{3}$ & 0,65 \\
\hline 8. & Spatial spread coefficient & 1 \\
\hline 9. & Coefficient of elasticity $\mathrm{K}_{4}$ & 0,26 \\
\hline 10. & Significance of risk & 0,25 \\
\hline 11. & Risk type & Acceptable risk \\
\hline
\end{tabular}

As you can see, this risk falls into the zone of acceptable risks, which requires proactive measures. As proactive measures, it is proposed to develop and adopt a program for the integrated development of territories, which will be aimed at reducing the importance of not only the studied, but also many other risks. In addition, the following are identified as priority tools for managing environmental and economic risks:

- development of the Concept of reclamation of disturbed lands,

- implementation of an integrated environmental management system for the Kuznetsk coal basin based on a comprehensive study of the functioning of the fuel and energy complex,

- the introduction of innovative technologies for dust suppression not only in the place of extraction of a mineral, but also along the entire chain of its movement to final consumption.

The most important areas of the concept are:

- development of ISEM - an integrated system of environmental monitoring, allowing to identify violations during reclamation, conduct a comprehensive assessment of land resources for degradation, etc .;

- development of mechanisms for increasing environmental responsibility;

- development of mechanisms for the integrated development of mineral deposits;

- development of mechanisms for the implementation of an integrated system of environmental management of the region.

Eco-oriented development of new technologies for coal mining can be carried out by the forces and means of the coal companies themselves or on their order. The development of holistic policy technologies aimed at solving environmental problems should be the content of the federal target program for the development of the coal industry in the Russian Federation.

Several mineral deposits are concentrated in the Kuznetsk coal basin. An example is the Karakan coal deposit. Coal mining at this deposit is carried out by several coal companies at once: JSC UK Kuzbassrazrezugol, JSC Kuzbasskaya Toplivnaya Company, CJSC Razrez Mayskiy, etc., for each of which the boundaries of land allotments have been established. The boundaries of land allotments significantly exceed the boundaries of mountain ones, since additional areas are needed for overburden, technological roads, etc. At the same time, the withdrawn area of land resources increases significantly. The program for the integrated development of mineral deposits would allow the most efficient use of land resources. For example, overburden from one company could be used to backfill the minedout area of another coal company. Thus, the area allocated for overburden would be freed up, which would reduce the technogenic load as a whole. 


\section{Conclusion}

Thus, the proposed methodology for a comprehensive assessment of environmental and economic risks based on a matrix of risk indicators allows us to take into account both the likelihood of the occurrence of risk and the significance of the consequences. As a result, for all identified risks, a two-component indicator can be obtained, which can be used as a basis for making management decisions.

The proposed mechanism for managing environmental and economic risks based on the results of assessing the identified impact takes into account all the identified drawbacks of interaction between regional legislative and executive authorities, regulatory bodies and subjects of negative environmental impact. Its implementation will significantly reduce the impact of environmental and economic risks on sustainable economic development.

\section{Reference}

1. T. Galanina, T. Koroleva, M. Baumgarten, E. Kucherova, M. Korolev, IOP Conference Series: Materials Science and Engineering, 62005 (2019).

2. T. Kiseleva, V. Mikhailov, G. Mikhailov, IOP Conference Series: Earth and Environmental Science, 84, 012044, 1 (2017).

3. V. Mikhailov, N. Golofastova, T. Galanina, T. Koroleva, Ya. Mikhailova, IOP Conference Series: Earth and Environmental Science, 50, 012038, 1 (2017).

4. V. Mikhailov, A. Koryakov and G. Mikhailov, Journal of Mining Science, 51, 5, 930 (2015).

5. A. Shinkevich, A. Lubnina, A. Koryakov, V. Mikhailov, E. Vodolazhskaya, International Review of Management and Marketing, 6, 2, 328 (2016).

6. T. Kiseleva, V. Mikhailov, V. Karasev, IOP Conf. Series: Earth and Environmental Science, 45, 012013, 1 (2016) 